Journal of Social Science 3(4): 237-244, 2007

ISSN 1549-3652

(C) 2007 Science Publications

\title{
Investigating the Causality Granger Relationship between the Rates of Interest and Inflation in Iran
}

\author{
Mansour Zarra Nezhad and Ruhollah Zarea \\ Faculty of Economics and Social Sciences, Shahid Chamran University (SCU), Ahvaz, Iran
}

\begin{abstract}
With regard to the importance of the rates of interest and inflation in economy, this paper aims at investigating the Granger causality relationship between the rates of interest and inflation in Iran's economy. Toda and Yamamoto's Granger test of causality as well as ARDL approach were used to test the hypothesis that the rate of interest is the Granger cause of the rate of inflation. The studied period is 1959-2002. The results show that in Iran's economy, the rate of (official and non-official) interest is the cause of inflation and not vice versa. This has been confirmed by both of these approaches and can be taken into consideration in Islamic banking.
\end{abstract}

Keywords: Interest, inflation, causality, Islamic banking

\section{INTRODUCTION}

Capital is one of the chief factors of the growth and development of the economy. Banks and financial associations, in this regard, can play a fundamental role in the equipment, maintenance and organization of the deposits for investment. In economics, the rate of interest is defined as the sum of money which is awarded to deposit makers or money lenders. The rate of interest is determined by many factors. Inflation, for instance, is one of the factors influencing the rate of interest; since inflation reduces the purchase power and the value of money (especially in long term financial contracts). Therefore, compensating for the devaluation of money has long been become of the interest of banks, and the inflation rate is considered as one of the important issues in economy.

The aim of this study is to test the causal relationship between the rates of interest and inflation in the usury-free banking system of Iran. This research, thus, hypothesizes that the rate of interest is the cause of inflation. In this study the mean of interest rates in long term deposits as well as the inflation rates during 1959-2002 are used.

\section{MATERIALS AND METHODS}

Investigating the relationship between the rates of nominal and real interests has a long history. This goes back to 240 years ago when Douglas propounded it before the $1740 \mathrm{~s}$, and when Thornton used it as a theory to explain this relationship. Afterwards, the analysis of interest was established in terms of nominal and real rates. This method, however, did not have the needed clarity, accuracy and analytic framework until the time of Fisher. This, of course, does not mean that there were no other economists to have discussed the relationship between the nominal and real rates of interest during the period ( 86 years) between these two economists. During this period four economists, namely Mill, Marshal, Haas, and Clark dealt with this issue.

Mill $^{[1]}$ in his book The Principles of Political Economy expects that in determining the rate of interest, the reduction of the value of money (the sum which is lent) caused by inflation be taken into consideration in addition to the expected rate of interest. According to Mill, inflation reduces the real rate of interest as well as the value of the principal loan. Therefore, the effect of inflation on the rate of interest and the principal loan should be taken into account. Prior to this, economists only considered the reduction of the value of the principal loan ${ }^{[2]}$.

After Mill, Marshall ${ }^{[3]}$ clearly dealt with nominal and real rates of interest and paid due attention to the reduction of the value of the real rate of interest and the principal loan due to inflation in calculating the rate of interest. In essence, he calculated the rate of real interest using the following formula though he did not specify the formula: $r=n-p-n p$, in which $r$ indicates the rate of real interest, $n$ is the rate of nominal interest, $p$ is the rate of inflation, and $n p$ is the crossed effect of the two mentioned rates which shows the effect of inflation on the real value of the received interest.

Haas $^{[4]}$ also wrote that the expected rate of interest, considering the alteration of the value of money,

Corresponding Author: Mansour Zarra Nezhad, Faculty of Economics and Social Sciences, Shahid Chamran University, Ahvaz, Iran, Tel: +611-3331216, Fax: +611-3337411 
includes these elements: the award of lending the capital, the award of risk, and the compensation for the fluctuations of purchase power.

Clark $^{[5]}$ contrary to Marshall, considered the rate of real interest as constant and examined the effect of inflation on the rate of nominal interest. That is, the rate of nominal interest according to the rate of inflation should be changed to the extent that the rate of real interest remains stable. Therefore, according to the modification of the rate of nominal interest, the real variables will not be influenced by income distribution term, since in case the changes are predictable, both the lender and the borrower will not be affected by the alteration of purchase power of money.

Fisher $^{[6]}$ utilizing the studies conducted by prior economists, proposed the theory of inflation and interest. His theory has developed the previous studies at least on four bases. First, he formulized and presented the relation between the rate of interest and inflation as $r=n-p$. In other words, if a basket of goods could be bought for one dollar at the beginning of the year, the purchaser will have two choices. The first is to lend that one dollar with the rate of nominal interest $(n)$ for one year and get that basket. On the base of this choice, s/he should return the $1+n$ dollars of the principal loan and its interest by the end of the year. The second choice is to repay the basket of goods with the rate of real interest $(r)$ by the end of the year, whereas the price of each basket is $1+p$. Therefore, according to the second choice $(1+r)(1+n)$ dollars should be repaid. Considering these two choices we should have $r=n-p-n p$ If we extend this formula and solve it based on real or nominal rate of interest, $n=r+p+r p \quad$ will be obtained ${ }^{[6]}$. Fisher further discussed that according to the last formula, if saving money is costly, the rate of nominal interest will never be negative, since under such conditions due to individuals' preference to saving money over lending it with negative rate of interest, the rate of nominal interest can never go below zero. Thus, if the rate of nominal interest cannot be below zero, the rate of inflation, by the same token, cannot be less than the rate of real interest.

Regarding the relationship between the rate of interest and inflation or the relationship between the rates of nominal or real interest, a great number of studies have been conducted. What follows is a brief investigation of some of these studies conducted recently.

Fisher's effect, or the relationship between the rates of short run interest and inflation, has been the subject of many economic and financial investigations. According to Fisher's effect, the rate of nominal interest must change in proportion to the expected inflation so that the real value of pecuniary streams is protected. This causes the rate of short run interest to be related to the superficial changes of price over the passage of time. Of course, Fisher's early hypothesis is silent on the extent of the effect of interest rate on the expected inflation, but it was later developed into different forms such as one-to-one effect (or Fisher's traditional hypothesis), over one-to-one effect ${ }^{[7]}$, below one-to-one effect ${ }^{[8]}$. Previous studies have commonly confirmed the relationship between the rate of interest and inflation. Studies such as those of Fama ${ }^{[9]}$, Nelson and Schwerk ${ }^{[10]}$, Mishkin ${ }^{[11,}$ 12] and Fama and Gibbons $^{[13]}$ can be cited in this regard. Some of the subsequent studies attempted to prove that the mentioned relationship is not robustly present in all cases and in all time periods. In this respect, studies such as those of Barsky ${ }^{[14]}$, Summers ${ }^{[15]}$, Mishkin ${ }^{[16]}$, Huizinga and Mishkin ${ }^{[17]}$, Estrella and Hardouvelis ${ }^{[18]}$, Kandel, Ofer and Sarig ${ }^{[19]}$, and Ghazali ${ }^{[20]}$ can be pointed to as some examples. Lardic and Mignon ${ }^{[21]}$ investigated the co-integration relationship between the rates of nominal interest and inflation for members of G7. Using Engle and Granger's ${ }^{[22]}$ concept of cointegration, they tested Fisher's hypothesis that the rate of nominal interest is equal to that of real interest plus the rate of the expected inflation. The results showed that there is a fractional co-integration relationship between the two variables of the rates of nominal interest and inflation across most members of G7. Such a relationship was not observed using the customary tests of co-integration. Berumont et al. ${ }^{[23]}$ investigated the relationship between the inflation uncertainty and the rates of interests in England. According to their study, the absence of a consensus in literature of economics about the direction of the impact of inflation uncertainty on the rates of interest may be due to the different origins of uncertainty. They investigated different types of inflation uncertainty (i.e., sudden uncertainty and steady state uncertainty) with different rates of interest in England. The results showed that when the total time period is studied, there is a positive correlation between the sudden uncertainty and the rate of interests but a negative one in case of steady state uncertainty. However, when the periods of curbing the inflation are considered, inflation uncertainty fully increases the rates of interests. Booth and Ciner ${ }^{[24]}$ investigated the relationship between the rates of 
interest and inflation in 9 European countries as well as the Unite States. Employing co-integration techniques, they found that except for one case, there was a cointegration relationship between the rates of interest and inflation among all other cases. This relationship is in accordance with Fisher's hypothesis in the long run. Meanwhile, there is a one-to-one co-integration relationship between the changes of the rate of the expected inflation and that of the interest. Borzoza and Brezezina $^{[25]}$ examined the long run relationship between the rates of real interest and inflation in Poland. They pointed out that there have been many research based on which monetary policies are determined by the rate of nominal interest. However, it is the rate of real interest which affects the expenses of corporations, households and consequently the inflation itself. In this article the long run relationship between the rates of interest and inflation has been investigated making use of the findings of Hallman, Porter and Small's ${ }^{[26]}$ research. The findings of the research indicate the effect of the long run gap between the rates of real and nominal interests on inflation. Feve and Auray ${ }^{[27]}$ investigated the concurrent manner of the rate of nominal interest and the expected inflation in a model with price cohesion, exogenousness of the growth of money and technical leaps. They investigated the relationship between the rate of nominal interest and that of the expected inflation using the above model and the method estimating instrumental variables. The results suggest a long run relationship between the rates of nominal interest and the expected inflation when the supply of money is exogenous. Milion ${ }^{[28]}$ tested the long run relationship between the rates of nominal interest and inflation using data from the United States. Based on the results, he declared that policy makers of the Central Bank who were in favor of fixed-price policy, arrange their undertakings according to inflation levels. That is, they would decrease the rate of nominal interest when inflation is at an endurable level whereas when the rate of interest is high, financial officials will change the rate of nominal interest in such a way to lead to an acceptable decrease of inflation rate. These results demonstrate why Fisher's effect is strong in some periods and weak in some others. When the rates of interest and inflation have the same trend and consequently there is a high correlation between these two variables, Fisher's effect will be strong in the long run. However, these two variables have random concurrent trends and a low co-integration, Fisher's effect will be weak in the short run. Taken as a whole, the results of this research confirm Irving Fisher's primary theory regarding the existence of a relationship between the rates of interest and inflation.

Having briefly reviewed the conducted studies on the relationship between the rates of interest and inflation, we will investigate the relationship between the rates of interest and inflation in Iran's economy. In other words, the mutual effect of the rates of interest and inflation in free-interest banking of Iran will be examined. In order to investigate and test the relationship between the rates of interest and inflation, Granger's test of causality is used in this research.

Standard Granger's Test Of Causality: Standard Granger's test of causality ${ }^{[29]}$ holds that if, by using the past quantities of $X_{t}, Y_{t}$ is estimated more accurately (than in case the past quantities of $X_{t}$ are not used), $X_{t}$ will be the Granger cause of $Y_{t}$. To test the hypothesis that $X_{t}$ is not the Granger cause of $Y_{t}$, a VAR model is produced as follows:

$Y_{t}=\sum_{i=1}^{k} \alpha_{i} Y_{t-i}+\sum_{i=1}^{k} \beta_{i} X_{t-i}+u_{t}$

where, if $\beta_{i}=0$ for $i=1,2, \ldots, k, \mathrm{X}_{\mathrm{t}}$ is not the Granger cause of $\mathrm{Y}_{\mathrm{t}}$. Of course, the length of the lag $k$ is to some extent optional. The validity of the test depends on the rank of VAR model and the variables' being stationary or non-stationary ${ }^{[30]}$. If variables are stationary, validity will be reduced. According to Granger ${ }^{[31]}$, this test is valid as long as the variables are not co-integrated. Thus, we should first examine the variables' being stationary or non-stationary, and then investigate the co-integration relationship between them. If the variables are first-degree stationary and not co-integrated, a VAR model can be formed based on the first difference of the variables, and then the test is performed.

Meanwhile, the results of Granger's test of causality are too sensitive to the selection of the length of lag. If the length of the selected lag is shorter than the actual length of the real lag, extra lags in VAR model will make the estimations inefficient ${ }^{[32]}$. Therefore, the principal problem of Granger's standard test of causality is so sensitive to the selection of the length of lag, so that different lengths of lag will bring about different results. Thus, Hsiao ${ }^{[33]}$ proposed a systematic autoregressive approach for selecting the optimum length of lag for each variable.

\section{HSIAO'S GRANGER CAUSALITY TEST}

Selecting the optimum length of lag using Hsiao's Granger causality test is done through two levels. In the 
first level, a set of autoregressions are estimated based on the dependant variable. In the first regressive equation, the dependant variable will have one lag and successively one lag will bee added to the subsequent regressions. The number of the estimated regressions will be: $(1+n)=(1+p)(1+r)$.

Selecting the length of lag is based on the sample size and the type of economic process under investigation. It is more convenient to select $m$ as large as possible. Therefore, the Final Prediction Error (FPE) for each regression is calculated as follows:

$Y_{t}=\sum_{i=1}^{k} \alpha_{i} Y_{t-i}+\sum_{i=1}^{k} \beta_{i} X_{t-i}+u_{t}$

where $\mathrm{T}$ is the sample size and ESS is the sum of squared errors. The length of the optimum lag $\left(m^{*}\right)$ will be the length of the lag which create the minimum FPE. In the second level, when $m^{*}$ is determined, the regressive equations with lags exerted on other variables are estimated as follows:

$Y_{t}=\alpha+\sum_{i=1}^{m} \beta_{i} Y_{t-i}+\varepsilon_{1 t}$

Then, the FPE for each regressive equation is calculated as follows:

$\operatorname{FPE}\left(\mathrm{m}^{*}\right)=\frac{\mathrm{T}+\mathrm{m}+1}{\mathrm{~T}-\mathrm{m}-1} \cdot \frac{\mathrm{ESS}(\mathrm{m})}{\mathrm{T}}$

Here, the length of the optimum lag of the variable $\mathrm{X}$ is the length of the lag which minimizes the FPE.

Now, to perform Hsiao's Granger causality test, FPE $\left(m^{*}\right)$ and FPE $\left(m^{*}, n^{*}\right)$ are compared. If FPE $\left(m^{*}\right)$ $<\operatorname{FPE}\left(m^{*}, n^{*}\right)$, then $X_{t}$ is not the Granger cause of $Y_{t}$ However, if $\operatorname{FPE}\left(m^{*}\right)>\operatorname{FPE}\left(m^{*}, n^{*}\right)$, then $X_{t}$ is the Granger cause of $Y_{t}$. In Hsiao's Granger causality test all the variables must be stationary, and in case they were not, there difference must be calculated so that they become stationary, and then the stationary difference is used in the test ${ }^{[33]}$.

It is obvious that before performing Hsiao's Granger causality test, tests of unit root and cointegration must be carried out. However, unit root tests are not robust. Nor are co-integration tests such as Johnson $^{[34]}$ reliable for small samples. Therefore, this would create bias in doing Hsiao's Granger causality test. Toda and Yamamoto ${ }^{[35]}$ proposed an approach for conducting this test by virtue of which it is possible to safeguard against the aforementioned deficiencies.

\section{CAUSALITY TEST OF TODA-YAMAMOTO (TY)}

Toda and Yamamoto ${ }^{[35]}$ proposed a simple approach based on estimating a modified VAR model in order to investigate Granger's test of causality. This approach, as they argue, is valid even if there is a co-integrative relationship between the variables. In this approach, the number of optimum lags $(k)$ of VAR model and the maximum degree of integration $\left(d_{\max }\right)$ must first be determined. Then a VAR model having $\left(K+d_{\max }\right)$ lags should be created. Of course, the process of selecting the lag is valid as long as $K \geq d_{\max }$. Thus, if we consider the following two-variables model and assume that $K+\mathrm{d}_{\max }=2$, then we will have:

$Y_{t}=\alpha+\sum_{i=1}^{m^{*}} \beta_{i} Y_{t-i}+\sum_{j=1}^{n} \gamma_{j} X_{t-j}+\varepsilon_{2 t}$

where $\left[\begin{array}{l}e_{1 t} \\ e_{2 t}\end{array}\right]$ is the vector of disturbance terms and is of white-noise type.

For example, to test the hypothesis that $\mathbf{X}_{2}$ is not the Granger cause of $\mathbf{X}_{1}, H_{0}: \alpha_{12}^{(1)}=\alpha_{12}^{(2)}=0$ is tested. The statistics used here is Wald statistics which has asymptotic $\chi^{2}$ distribution with a degree of freedom equals to the number of zero limitations. The statistics used in this test is valid regardless of whether or not $X_{1 t}$ and $X_{2 t}$ are stationary or co-integrated of any degree.

Zapata and Rambaldi ${ }^{[36]}$ deem this approach to be advantageous so that there is no need of being familiar with the characteristics of co-integration techniques, and that only knowing the rank of VAR model as well as the degree of maximum integration of the variables for performing Granger's test of causality would suffice. In addition to this approach, ARDL approach is also proposed for doing Granger's test of causality.

\section{ARDL APPROACH}

ARDL approach was proposed by Pesaran et al. ${ }^{[37]}$. One of the merits of this method is that in addition to determining the number of co-integration vectors, contrary to Johnson's approach, there is no need to know the degree of co-integration of the variables of the model. According to this approach, the following equations are estimated in order to investigate the cointegrative relationship between $X_{t}$ and $\mathrm{Y}_{\mathrm{t}}$.

$$
\operatorname{FPE}\left(m^{*}, n\right)=\frac{T+m^{*}+n+1}{T-m^{*}-n-1} \cdot \frac{\operatorname{ESS}\left(m^{*}, n\right)}{T}
$$

where $\Delta$ represents the operator of subtraction, $X$ the dependant variable, $Y$ the vector of independent variables, $\varepsilon_{1}$ the disturbance term, $t$ the time indicator, and $R$ is the number of optimum lags which can be determined using criteria of Akaik (AIC), Schwarz- 
Bayesian (SBC), Hanan-Quin (HQC) or $\bar{R}^{2}$ The coefficients $a_{1}, b_{i l}, c_{i l}, \sigma_{1}$ and $\sigma_{2}$ are parameters.

$$
\begin{aligned}
& {\left[\begin{array}{l}
e_{1 t} \\
e_{2 t}
\end{array}\right]+\left[\begin{array}{l}
x_{1, t-2} \\
x_{2, t-2}
\end{array}\right]\left[\begin{array}{ll}
\alpha_{11}^{(2)} & \alpha_{12}^{(2)} \\
\alpha_{21}^{(2)} & \alpha_{22}^{(2)}
\end{array}\right]+\left[\begin{array}{l}
x_{1, t-1} \\
x_{2, t-1}
\end{array}\right]\left[\begin{array}{ll}
\alpha_{11}^{(1)} & \alpha_{12}^{(1)} \\
\alpha_{21}^{(1)} & \alpha_{22}^{(1)}
\end{array}\right]} \\
& +\left[\begin{array}{l}
\alpha_{10} \\
\alpha_{20}
\end{array}\right]=\left[\begin{array}{l}
x_{1 t} \\
x_{2 t}
\end{array}\right]
\end{aligned}
$$

where $\mathrm{Y}$ is the dependant variable, $\mathrm{X}$ the vector of independent variables, and $\mathcal{E}_{2}$ the disturbance term.

The null hypothesis holding that there is no relationship between the variables $\left(H_{0}: \sigma_{1}=\sigma_{2}=0\right)$ is tested against the alternative hypothesis $\left(H_{1}: \sigma_{1} \neq \sigma_{2} \neq 0\right)$ using $\mathrm{F}$-statistics $\mathrm{F}_{\mathrm{X}}(\mathrm{X} \mid \mathrm{Y})$. However, the (asymptotic) distribution of F-statistics is not standard without considering the independent variables being $\mathrm{I}(0)$ or I(1). In this regard, Pesaran et al. ${ }^{[37]}$ generated and presented the appropriate critical values according to the number of independent variables in the model of presence or absence of constant term or time trend in the model. These statistics include two sets (columns). One set is calculated assuming that all the variables are $\mathrm{I}(0)$, and the other based on the assumption that all the variables are I(1). If the calculated F-statistics exceeds the limits of critical zone presented by Pesaran et al., the null hypothesis, that there is no long run relationship between the variables, is rejected. In this case, it can be deduced that there does exist a one-way Granger causal relationship between the variables. Finally, if the calculated F-statistic is within the limits of the critical zone, the results will be indefinite and not deducible. The same approach will be adopted regarding the other equation.

\section{RESULTS AND DISCUSSION}

Toda-Yamamoto's and ARDL tests are used to investigate Granger causal relationship between the variables. The results of these two approaches will be compared. As indicated earlier, this paper aims at investigating Granger causal relationship between the rates of interest and inflation in Iran. The variables used in this model are: the rate of interest and the rate of inflation. The rate of inflation (INF) is measured using the price index of goods and services in the fixed price of the year 1997. Two types of official and non-official rates of interest are considered in this study. The former (INT) is measured by the amount of the interest of the deposits of long term investment and the latter is determined by the market.
Since in Toda-Yamamoto method, we need to know about the degree of integration of the variables, Agmented Dickey-Fuller (ADF) test is used to test the variables' staionarity. The results of this test are summarized in Table 1. As seen in this table, both of the variables are non-stationary. The variables of the rate of official interest and the rate of inflation will be stationary by differencing them once and twice, respectively.

Table 1: Results of unit root test of the variables

\begin{tabular}{ccccccc}
\hline Variable & \multirow{2}{*}{ Intercept } & $\begin{array}{c}\text { Calc. } \\
\text { st. }\end{array}$ & Lags & Trend & $\begin{array}{c}\text { Mac. } \\
\text { st. }\end{array}$ & sig. \\
\hline INT & $\times$ & -2.28 & 0 & $\times$ & -3.52 & $5 \%$ \\
INF & $\times$ & -1.16 & 3 & $\times$ & -3.52 & $5 \%$ \\
DINT* & $\times$ & -6.7 & 0 & - & -2.93 & $5 \%$ \\
DINF* & $\times$ & -0.23 & 2 & $\times$ & -3.52 & $5 \%$ \\
DDINF* & $\times$ & -6.79 & 1 & - & -2.93 & $5 \%$ \\
\hline
\end{tabular}

* Stationary (D is the operator of differentiation).

To investigate Granger causal relationship between inflation (INF) and the rate of official interest (INT), a VAR model with three lags is used. The number of lags (3) is obtained by summing the rank of the VAR model and the maximum integration degree. The rank of the VAR model, according to Schwarz-Bayesian criterion $(\mathrm{SBC})$ is one as follows:

$\Delta X_{t}=a_{1}+\sum_{i=1}^{k} b_{i 1} \Delta X_{t-i}+\sum_{i=1}^{k} c_{i 1} \Delta Y_{t-i}+\sigma_{1} X_{t-1}+\sigma_{2} Y_{t-1}+\varepsilon_{1 t}$

Table 2 illustrates the results of Wald test regarding the significance of the coefficients with lags of the variables.

Table 2: Granger causality of INF and official INT

\begin{tabular}{ccccc}
\hline Dep. & Indep. & $\mathrm{H}_{0}$ & $\begin{array}{c}\text { Wald- }\left(\chi^{2}\right) \\
\text { st. }\end{array}$ & Result \\
\hline INF & INT & $\beta_{l i}=0(i=1,2$, & $11.65(0.009)$ & $I N T \rightarrow I N F$ \\
INT & INF & $\begin{array}{c}3) \\
\alpha_{2 i}=0\end{array}$ & $3.49(0.322)$ & $I N F \mapsto I N T$ \\
\hline
\end{tabular}

Note: The numbers in parentheses indicate the p-value

As depicted in Table 2, the rate of official interest is the Granger cause of inflation, but not vice versa.

ARDL approach also is used to test, the existence of a long run equilibrium relationship between the rates of official interest and inflation. The advantage of this approach is that in addition to determining the number of co-integration vectors, contrary to Johnson's approach, there is no need to know the degree of integration of the variables of the model. To this end, equations in the following form, where INT is the rate of official interest and INF is the rate of inflation, are estimated. 
$\Delta \mathrm{INF}_{\mathrm{t}}=\mathrm{a}_{2}+\sum_{\mathrm{i}=1}^{\mathrm{k}} \mathrm{b}_{\mathrm{i} 2} \Delta \mathrm{INT}_{\mathrm{t}-\mathrm{i}}+\sum_{\mathrm{i}=1}^{\mathrm{k}} \mathrm{c}_{\mathrm{i} 2} \Delta \mathrm{INF}_{\mathrm{t}-\mathrm{i}}+\omega_{1} \mathrm{INT}_{\mathrm{t}-1}+\omega_{2} \mathrm{INF}_{\mathrm{t}-1}+\varepsilon_{2 \mathrm{t}}$

The null hypothesis that there is no long relationship between the variables is tested against the alternative hypothesis using $\mathrm{F}_{\mathrm{INF}}$ (INF|INT).

Table 3: Granger causality of INF and official INT

\begin{tabular}{ccc}
\hline F-statistics & \multicolumn{2}{c}{$I(1)$} \\
& \multicolumn{2}{c}{$I(0)$} \\
\hline$F_{I N F}(I N F \mid I N T)=7.67$ & 4.934 & 5.764 \\
$F_{I N F}(I N T \mid I N F)=1.92$ & 4.934 & 5.764 \\
\hline
\end{tabular}

As seen in Table 3, the calculated F-statistics in case $F_{I N F}(I N F \mid I N T)$ is above the limits of critical values at 95 percent level. As a result, only in this case is there a long run relationship between the variables at this level of confidence, and it can be deduced that there does exist a one-way Granger causal relationship from the rate of official interest to the rate of inflation. This result confirms the result of Toda-Yamamoto's approach.

Since the data for the rates of non-official interest are different from the official interest, we investigate, here, the Granger causal relationship between the rates of non-official interest and inflation applying the two mentioned approaches.

$\mathrm{ADF}$ test showed that the rates of non-official interest and inflation are non-stationary and both became stationary by differencing them once and twice, respectively. According to Yamamoto's approach, the result is as follows.

Table 4: Granger causality of INF and non-official INT

\begin{tabular}{ccccc}
\hline Dep. & Indep. & $\mathrm{H}_{0}$ & $\begin{array}{c}\left(\chi^{2}\right) \\
\text { Wald-st. }\end{array}$ & Result \\
\hline \multirow{2}{*}{ INF } & INT & $\beta_{l i}=0(i=1,2,3)$ & $\begin{array}{c}(0.005 \\
12.74\end{array}$ & INT $\rightarrow$ INF \\
& & & $\begin{array}{c}(0.773) \\
1.12\end{array}$ & INF $\mapsto$ INT \\
INT & INF & $\alpha_{2 i}=0$ &
\end{tabular}

Note: The numbers in parentheses indicate the p-value

As shown, the rates of non-official interest is the Granger cause of inflation and not vice versa.

ARDL approach is also used to test the same relationship. This approach results in the following outcomes.

Table 5: Granger causality of INF and non-official INT

\begin{tabular}{ccc}
\hline F-statistics & \multicolumn{2}{c}{$I(1)$} \\
& \multicolumn{2}{c}{$I(0)$} \\
\hline$F_{I N F}(I N F \mid I N T)=8.33$ & 4.934 & 5.764 \\
$F_{I N F}(I N T \mid I N F)=0.117$ & 4.934 & 5.764 \\
\hline
\end{tabular}

As shown in Table5, the calculated F-statistics in case $F_{I N F}(I N F \mid R)$ is above the critical values at 95 percent level. Therefore, there will be a long run relationship between the variables at this level of confidence, and it can be deduced that there is a oneway Granger causal relationship from the rates of nonofficial interest to the rates of inflation but not vice versa. In other words, the rates of non-official interest is the cause of inflation, but inflation is not the cause of the rates of non-official interest. This result is consistent with the result of Toda-Yamamoto approach and both approaches confirm the results of one another.

\section{CONCLUSION}

The aim of this study was to investigate the causal relationship between the rates of interest and inflation in Iran's economy during 1959-2002. Due to its rigor and efficiency, Toda-Yamamoto approach was used. In addition to this approach, ARDL test presented by Pesaran et al. ${ }^{[37]}$ was also employed. The results obtained from Toda-Yamamoto approach show that there is a one-way causal relationship from the rates of interest to the rates of inflation, but not vice versa. Thus, the rate of interest can be the cause of the rates of inflation, but the rates of inflation cannot be the cause of the rates of interest in Iran's economy. This was also confirmed by ARDL approach. According to the results, the research hypothesis that the rates of interest is the Granger cause of the rates of inflation is strongly confirmed, since not only is the rates of interest considered to be the Granger cause of inflation, but also this relation is one-way, and the rate of inflation is not the Granger cause of the rate of interest. This one-way causal relationship is true for both official and nonofficial rates of interest.

Therefore, it can be observed that based on both Toda-Yamamoto and ARDL approaches, the rates of interest (both official and non-official) is the Granger cause of inflation, but inflation is not the Granger cause of the rates of interest (either official or non-official); that is, the hypothesis advanced in the introduction cannot be rejected.

This can have implications for those interested in Islamic banking in Iran or other countries. Determining the rates of interest or the rates of deposits and bank loans is one of the important theoretical and executive aspects of Islamic banking. Some scholars consider the high rates of inflation as the cause of the high rates of interest in Iran's economy, while others deem the high rates of interest to be the cause of high rates of inflation. 


\section{REFERENCES}

1. Mill, John Stuart, 1848. Principles of Political Economy, 6th ed. Longmans, Green and Co, London, pp: 649-650.

2. Humphery, Thomas M., 1983. The Early History of the Real/Nominal Interest Rate Relationship. Economic Review, 69(3): 2-10.

3. Marshall, Alfred, 1887. Remedies for Fluctuations in General Prices. Contemporary Review, March. Reprinted In: Memorials of Alfred Marshall (ed A. Pigou, 1925) pp. 188-211. Macmillan, London.

4. De Haas, Jacob A., 1889. A Third Element in the Rate of Interest. Journal of the Royal Statistical Society, Series A (52): 99-116.

5. Clark, John B., 1895. The Gold Standard of Currency in the Light of Recent Theory. Political Science Quarterly, 10(3): 383-397.

6. Fisher, Irving, 1896. Appreciation and Interest. New Macmillan, York.

7. Darby, M.R., 1975. The Financial and Tax Effects of Monetary Policy on Interest Rates. Economic Enquiry, 13(2): 266-276.

8. Tobin, J., 1965. Money and Economic Growth. Econometrica, 33(4): 671-84.

9. Fama, E.F., 1975. Short-Term Interest Rates as Predictors of Inflation. The American Economic Review, 65(3): 269-82.

10. Nelson, C.R. and G.W. Schwert, 1977. Short-Term Interest Rates as Predictors of Inflation: On Testing the Hypothesis that the Real Rate of Interest Is Constant. American Economic Review, 67(3): 478486.

11. Mishkin, Frederic S., 1981. Understanding Real Interest Rates. NBER Working Papers, 2691, National Bureau of Economic Research, Cambridge, MA.

12. Mishkin, Frederic S., 1988. The Information in the Term Structure: Some Further Results. Journal of Applied Econometrics, 3(4): 307-314.

13. Fama, E. F. and M. R. Gibbons, 1982. Inflation, Real Returns and Capital Investment. Journal of Monetary Economics, 9(3): 297-323.

14. Barsky, R.B., 1987. The Fisher Hypothesis and the Forecastability and Persistence of Inflation. Journal of Monetary Economics, 19(1): 3-24.

15. Summers, L.H., 1983. The Non-adjustment of Nominal Interest Rates: A Study of the Fisher Effect. In: A Symposium in Honor of Arthur Okun (ed James Tobin) pp. 210-244. Brookings Institution, Washington D.C.
16. Mishkin, F.S., 1984. The Real Interest Rate: A Multi-country Empirical Study. Canadian Journal of Economics, 7(2): 283-311.

17. Huizinga, John and Frederic S. Mishkin, 1986. Monetary Policy Regime Shifts and the Unusual Behavior of Real Interest Rates. NBER Working Papers 1678, National Bureau of Economic Research, Cambridge, MA.

18. Estrella, Arturo and Gikas A. Hardouvelis, 1991. The Term Structure as a Predictor of Real Economic Activity. Journal of Finance, 46(2): 555576.

19. Kandel, Shmuel, Aharon Ofer and Oded Sarig, 1996. Real Interest Rates and Inflation: An Ex-ante Empirical Analysis. Journal of Finance, 51(1): 205225.

20. Ghazali, Noor A. and Shamshubariah Ramlee, 2003. A Long Memory Test of the Long-Run Fisher Effect in the G7 Countries. Applied Financial Economics, 13(10): 763-769.

21. Lardic, S. and V. Mignon, 2003. Fractional Cointegration between Nominal interest Rate and Inflation: A Re-examination of the Fisher Relationship in the G7 Countries. Economic Bulletin, 3(14): 763-769.

22. Engle, R.F. and C.W.J. Granger, 1987. Cointegration and Error-Correction: Representation, Estimation and Testing. Econometrica, 55(2): 251276.

23. Berument, H., 1999. The Impact of Inflation Uncertainty on Interest Rates in the UK. Scottish Journal of Political Economy, 4(2): 207-218.

24. Booth, G. Geoffrey and Ciner, Cetin, 2001. The Relationship between Nominal Interest Rates and Inflation: International Evidence. Journal of Multinational Financial Management, 11(3): 269280.

25. Brazoza Brzezina, M., 2001. The Relationship between Real Interest Rate and Inflation. Research Department, WP 23, National Bank of Poland.

26. Hallman, J., R. Porter, Small, D., 1991. Is the Price Level Tied to the M2 Monetary Aggregate in the Long Run? American Economic Review, 81(4): 841-858.

27. Fave, P. and S. Auray, 2002. Interest Rate and Inflation in Monetary Models with Ingenious Money Growth Rate. Economic Bulletin, 5(1): 110 .

28. Million, N., 2003. Shifting Regimes in the Relationship between Interest Rates and Inflation. Proceeding of the $2 \mathrm{~d}$ International Conference on Economic Policy Modeling. Istanbul Bilgi University. Istanbul.<http://www.ecomod.net/conferen ces/ecomod2003/ecomod2003_papers.htm> 
29. Granger, C.W.J., 1969. Investigating Causal Relation by Econometric and Cross-Sectional Method. Econometrica, 37(3): 424-438.

30. Geweke, J., 1984. Inference and Causality in Economic Time Series Models. Handbook of Econometrics, Vol. 2, Amsterdam, North Holland.

31. Granger, C.W.J., 1986. Development in the Study of Co-integrated Economic Variables. Oxford Bulletin of Economics and Statistics, 48(3): 213228.

32. Cheng, B.S. and T.W. Lai, 1997. An Investigation of Co-integration and Causality between Energy Consumption and Economic Activity in Taiwan. Energy Economics, 19(4): 435-444.

33. Hsiao, C., 1981. Autoregressive Modeling and Money-Income Causality Detection. Journal of Monetary Economics, 7(1): 85-106.
34. Johansen S., 1991. Estimation and Hypothesis Testing of Co-integration Vectors in Gaussian Autoregressive Models. Econometrica, 59(6): 1551-1580.

35. Toda, H.Y., T. Yamamoto, 1995. Statistical Inference in Vector Autoregressions with Possibly Integrated Processes. Journal of Econometrics, 66(1-2): 225- 250.

36. Zapata, H.O. and A.N. Rambaldi, 1997. Monte Carlo Evidence on Co-integration and Causation. Oxford Bulletin. Economic Statistics. 59 (2): 285 298.

37. Pesaran, M.H., Y. Shin and R.J. Smith, 1996. Testing for the Existence of a Long Run Relationship. Cambridge Working Paper in Economics, 9622, Faculty of Economics, University of Cambridge, Cambridge. 